\title{
Watching the FIFA World Cup 2010 in England: the sojourner perspective
}

Ian Jones, Lorraine Brown* and Steven Richards

School of Tourism, Bournemouth University, Poole, UK

(Received 18 March 2011; final version received 3 September 2012)

\begin{abstract}
Recent years have seen an emergence of a varied academic literature focused on the football fan, with a wealth of studies exploring issues such as hooliganism, fan behaviour and fan identification. No research, however, has documented the experiences and perspectives of the international sojourner, who follows the televised tournament far away from the home country. This paper offers a contribution to the literature on fandom by focusing on the experiences of becoming a temporary fan among a sample of nine international students in England during the period of the 2010 FIFA World Cup. It shows the importance of the tournament for students away from their home nation, acting as a point of celebration and as a means of bringing sojourners of the same nationality together to support their team. It reveals how the tournament offered escape from stress, became a focal point for social interaction, provided the opportunity for recreation of home, and for the reinforcement of feelings of national identity.
\end{abstract}

Keywords: temporary fans; sojourners; FIFA World Cup; escapism; social interaction; identity

\section{Introduction}

The aim of this paper is to explore how a particular type of sport consumer - the sojourner - experiences watching a sporting mega as a 'temporary fan' (Hunt, Bristol, \& Bawshaw, 1999) of the sport event whilst residing outside their own country. The sojourn is defined as temporary between-culture contact of between six months and five years; sojourners include international students, migrants and refugees (Ward, Bochner, \& Furnham, 2001). This paper examines their experiences of the 2010 FIFA Football World Cup within such a context, for whom 'the global game' of football possessing 'unparalleled cross-cultural appeal' (Giulianotti \& Robertson, 2004, p. 545), may provide a source of escape from, and a sense of belonging to, an unfamiliar, and often threatening setting.

The move to a new environment is cited as one of the most traumatic events in a person's life, and for most sojourners culture shock is inevitable (Hamburg \& Adams, 1967; Ward et al., 2001). Culture shock is defined as anxiety that results from losing the familiar signs and symbols of social intercourse and their substitution by other cues that are strange (Hall, 1959). Loneliness and homesickness are commonly enduring symptoms of culture shock. Indeed, culture shock is liked by

many writers to a period of mourning for the home world, characterized by feelings of grief and separation anxiety (Bock, 1970; Garza-Guerrero, 1974). Homesickness is well documented in studies of the international student experience (Brown \& Holloway, 2008). Loneliness, resulting sometimes in physical and mental illness, is also commonly intertwined with transition to a new culture (Owie, 1982; Ward \& Rana-Deuba, 1999).

Research on sojourner adjustment reveals that social interaction acts as a major contributor to emotional well-being, helping to ease homesickness and loneliness during the adaptation process (Brown, 2009a; Furnham \& Erdmann, 1995; Hamburg \& Adams, 1967; Ward \& Kennedy, 1999; Ward et al., 2005; Wiseman, 1997). However, student's expectations of interacting with the host are usually unfulfilled as contact is mostly described as rare or non-existent (Brown, 2009b; De Vita, 
2005; Furnham \& Erdman, 1995; Sovic, 2008; Spencer-Rodgers, 2001; Volet \& Ang, 1998; Ward et al., 2005). A lack of host contact is attributed by international students to perceived indifference on the part of domestic students (Sovic, 2008; Ward et al., 2005) and incidences of racism have also been reported (Brown, 2009b). Indeed, a pattern of ghettoisation has long been observed in the international student body, with interaction taking place within conational groups, and with the willingness to leave the confines of such groups being rare (Berry, 1994; Brown, 2009a; Gu, Schweisfurth, \& Day, 2008; Ward \& Chang, 1997). Insider explanations offered for the widespread phenomenon of conational interaction identified the following three factors: linguistic ease, emotional succour and instrumental support (Brown, 2009a).

Within this environment, it could be suggested that the sojourner would benefit from activity that provides an escape from stress, and interaction with the host. Sport would appear to provide, to varying degrees, opportunities for both. The benefits of watching sport as a form of stress relief have been well documented. As Smith and Stewart (2007, p. 159) have highlighted, 'sport watching is the ultimate escape experience', with escape from stress being a particularly important function, particularly for ethnic minority fans, who, according to Bilyeu and Wann (2002), use sport frequently for this purpose. In terms of interaction, mega events provide a particular opportunity for the sojourner. In the short term, at least, television coverage of mega events can create a version of 'the global village' (Roche, 2006), providing an opportunity for interaction between host and sojourner, based on a common sporting interest.

Although most research on watching sport has examined those fans with a more enduring sense of identity with a team or individual, it can also be recognised that for some, such as the sojourner, interest in a sport will be based on a specific event and time constrained by the period of that event. This is the concept of the 'temporary fan' (Hunt et al., 1999). One such time constrained, high profile event is that of the FIFA World Cup. This event takes place within a broader footballing context that has, as Guilianotti (2002) has noted, transformed over recent years in terms of mobility of its elite labour, the proliferation of global and continental competitions, new media outlets and new and varied forms of cultural encoding through those new outlets. Thus, football spectatorship is characterised by "the genesis of intensified flows between individuals, social groups, objects and institutions across an increasingly globalised terrain' (Giuilianotti, 2002, p. 29). Teams have become less representative of the geographical space within which they operate, and a greater flexibility is available to the fan in terms of how they identify with a chosen team, suggesting greater flexibility in forms of fandom. As a consequence, according to Guilianotti (2002), four ideal type categories of football fan can be identified. These are based on the two dimensions of hot-cool, or the extent to which the team is central to the individual's self-concept, and traditional-consumer, or the extent to which the identification with the team is more enduring, based on locality, history and, arguably, old fashioned values (traditional), or more flexible, driven by a market driven consumerism (consumer). Thus, supporters are traditional/hot spectators, representing historic values of football spectatorship, for example enduring identification with, and loyalty to, a single team, which is representative of the community. Loyalty is given, not based upon the success or failure of the team, and to switch allegiance is considered unthinkable. Followers (traditional/cool spectators) also remain focused on a single team, but for them, the team is a lesser aspect of the self-concept, and engagement may be through more indirect means, demonstrating a favourable interest rather than a committed set of behaviours such as regular attendance.

In addition to these 'traditional' forms of spectatorship, the commodification of 
football, largely through the growth of television (Miles, 1997) has led to more distant forms of spectatorship, with engagement with the team based upon consumption, rather than the membership implied of traditional fans. Thus to the hot/ consumer spectator, referred to by Guilianotti (2002) as a 'fan', the support of the team forms a significant aspect of the self-concept, but is enacted most readily through the consumption of the team through television, internet sites and merchandise. The team, and its players become celebrities, and are followed in much the same way as media celebrities, not only for performances on the pitch, but also their off field behaviour.

The fourth type is that of the cool/consumer or flaneur. The flaneur demonstrates fleeting relationships to teams, formed almost exclusively through media consumption. Once-favoured teams may be replaced with others who fulfil a short-term need, perhaps due to success on the pitch, or celebrity endeavour away from the pitch. Thus, the team becomes a true consumer product, with the flaneur able to switch easily between teams, or even away from the sport altogether. As a result, the team has no more significance to the self-concept as would any other consumer product.

As a typology with which to explore the nature of contemporary fandom, this is, as Gibbons and Dixon (2010), note, the most comprehensively theoretical and widely used typology, and would seem to be a useful framework with which to examine football fan identities with an important caveat. It is important not to see fans as simply belonging to one of Giulianotti's four types, instead it is important to acknowledge that fandom is much more fluid, and that where fans are placed at any one time 'will be contingent upon the specific conditions of any interaction' (Stone, 2007, p. 179). Here, Hunt et al.'s (1999) concept of the temporary fan is useful, suggesting that for an event with a finite duration, such as the 2010 World Cup, the individual will only be a fan for the period of that event and will return to normal patterns of behaviour once the event has ended. Using the typology as a guiding, rather than formal theoretical framework (Jones, Brown, \& Holloway, 2012), this paper explores the experiences of watching football by the international sojourner, who follows the televised tournament far away from their home country as a temporary fan.

Methodology

A qualitative approach was adopted as it offers the means through which to uncover the views, experiences and meanings held by participants (Daymon \& Holloway, 2011). The aim of the qualitative researcher is understanding and exploration, and in some cases the generation of theory (Daymon \& Holloway, 2011), especially within contexts that seek to understand the views of participants themselves, uncover the meanings that people give to their experiences and give voice to those within the study population, especially when exploring topics that are new or under researched (Hennink, Hutter, \& Bailey, 2011) such as that of the sojourner experience. Thus, such an approach is appropriate to understand how the sojourner experiences the World Cup outside their own country and how they perceive the new culture during a time of heightened patriotism. Where little is known about the subject, only a qualitative approach could fulfil the goal of understanding the international student experience of following the World Cup away from home. A semi-structured interview was used, as there were a number of topics that we wished to cover. A flexible interview guide was prepared covering the following topics: participants' allegiance to football, the impact of the World Cup on their day-to-day life in England and their impressions of England during June and July 2010. As Mason (2002) suggests, the semi-structured interviewer has a topic and an agenda, but they are open to new avenues of research and are flexible and spontaneous in terms of the lines of enquiry pursued. Interviews therefore differed 
among the participants in response to the issues of concern raised by them. Recurrent themes were identified during the analysis process, though there was predictably divergence in the emphasis placed by students on the relative importance of each theme.

Daymon and Holloway (2011) state that the research setting and the participants must be available and accessible. The research setting for this study was the Graduate School of a university in the south of England, which recruits an annual intake of around 200 international students. Access to the students was granted through a gatekeeper, in this case the head of department. Purposive sampling was used. Inclusion criteria for this study were any international student who was intending to follow the World Cup; a range of nationalities was sought so that a diversity of experience could be captured. All international students in the academic year 2009/ 2010 were invited by email to take part in an interview project on their experiences of watching the World Cup in England, if they were intending to watch the tournament in June/July 2010. Fifteen students responded positively, of which nine were categorised as temporary fans. There was some duplication of nationality, this reflects the self-selecting nature of the sample. Ideally, a maximal variation sample

Table 1. Sample characteristics.

French, 23, female, France, temporary fan

German, 22, female, Germany, temporary fan

German, 24, female, Germany, temporary fan

Greek, 44, male, Greece, temporary fan

Nigerian, 42, female, Nigeria, temporary fan

Tibetan, 25, male, England, temporary fan

Indian, 24, male, England, temporary fan

Indian, 31, male, England, temporary fan

Chinese, 26, male, England, temporary fan

(Jones et al., 2012) would have been adopted to ensure as a wide range of experiences as possible to be explored, but the opportunistic nature of the data collection precluded this. The profile below includes nationality, age, gender and the team participants supported during the tournament (Table 1).

Ethical approval to undertake this study came from the university's Research Ethics Committee; participants were assured of anonymity and confidentiality and of their right to withdraw from the project when volunteers were sought and at the start of the interview. The researchers did not mark students' work and had no input in assessment; furthermore no financial incentive was offered: these were important ethical considerations.

Interviews took place in one of the researchers' offices and were recorded by digital recorder. As advised by Mason (2002), interviewees' physical comfort was attended to: lighting was not too bright, seating was comfortable, a hot or cold drink was supplied, the phone was taken off the hook and a 'do not disturb' sign was put on the door. The demeanour of the researcher has an impact on the quality of the data generated as well as on the emotional comfort of the interviewee (O’Reilly, 2005), thus, we made sure that we were friendly and attentive, and that eye contact was maintained. This was also important in generating rapport, which enhances the quality of data generated (Hennink et al., 2011). O'Reilly (2005) advises that the interview should feel like a conversation with a friend, but as Mason (2002) mentions, the effort needed to sustain conversation in an interview can be tiring; this was particularly pertinent in this study as all interviews lasted between 60 and $90 \mathrm{~min}$. Interviews took place between June and July 2010, during 
the tournament itself when thoughts and feelings were fresh.

Thematic analysis was used to analyze the data. Thematic analysis consists of three steps (Holloway \& Wheeler, 2010). Firstly, interviews were transcribed in full. Secondly, a process of familiarisation took place whereby transcripts were read repeatedly so that a holistic impression of the data could be gained, permitting initial analysis to take place before data were broken up through the process of coding (Daymon \& Holloway, 2011). Thirdly, data reduction took place, whereby the data are coded. A code is an identifying name or label given to a data unit; it should be a distinct word so that it is obviously different from another code, and there must be a low level of inference (it must be close to concrete description). After all the data were coded, the process of sorting codes that are linked took place: similar codes were grouped together, leading to the emergence of a category; this is a conceptual label for a group of linked codes. The research categories that were formed following data coding therefore reflect participants' priorities. These formed the topics covered in the results section. As is acceptable in qualitative research, the literature review was processual (Mason, 2002), conducted at the start of the research and throughout in response to emergent themes.

With regard to the generalisability of findings, qualitative researchers acknowledge that a small sample and the selection of one case makes it difficult to move to general classifications (Mason, 2002). Nevertheless, they often claim that similar settings should produce similar data, such that theory-based generalisation, involving the transfer of theoretical concepts found in one situation to other settings and conditions, is possible (Daymon \& Holloway, 2011). The setting for this research permits the transfer of the findings to similar settings, namely, higher education institutions with a high number of international students and to communities with a diverse ethnic mix.

\section{Findings and discussion}

Being a temporary fan of a team does not contribute to the individual's enduring self-concept, and the temporary nature of fandom was reflected in the following interview extracts:

I'm not a big football fan but I do watch some games, especially when France is playing. (French student)

I'm not a big fan; it's more like a four year thing, it's more exciting, it's everywhere. (Tibetan student)

I don't follow clubs but with a big tournament like this I get excited. It's something global. (Nigerian student)

I've not been a football fan really. But we do watch specially during the World Cup. It happens every four years and we do get crazy about football then. (Indian student)

Guilianotti's typology is useful in being able to advance traditional dichotomous or dualistic typologies (e.g. high/low identification, fan/spectator) of fandom, however, it remains focused upon those who have an enduring relationship to football, even if it accounts for the differing nature of this relationship. As such, the temporary fan remains largely unexplored. The students cited above were not regular followers of a team, and anticipated that they would revert to their status as non-fans after the tournament had finished, thus demonstrating a short lived, event driven identity, as what Giulianotti would class as 'fans', with a market centred relationship to their chosen team, although without the stability of fan identification suggested by the 
typology. As Crawford (2003) indicates, the nature and composition of a supporter community are in constant flux, particularly in a media-saturated social context, and these participants demonstrate a temporary sense of fandom based on unidirectional consumption, not only through television coverage, but also, significantly through the Internet, rather than a deeper rooted membership or sense of 'belonging'. The key outcome of such consumption to emerge from the analysis for fans was an opportunity for escape. For the sojourner, the data demonstrated the need for relief from the heavy demands of academic life, as reflected below:

It's so nice to do something different from what I normally do, working in the library, thinking about my dissertation all the time, it's great to have a break from that. (Indian student)

As the terms 'holiday', and 'break' suggest, the idea of escape is related to what Wann, Melnick, Russell, and Pease (2001) describe as over stimulation. The idea of escaping from over, rather than under stimulation is supported by Wann, Allen, and Rochelle (2004), who determined that, for university students, escape from over stimulation was significantly more prevalent. Thus participants were escaping stressful or difficult experiences, more than seeking the emotional arousal and excitement that were missing from their everyday lives (Elias \& Dunning, 1986). This resonates with Segrave's (2000) suggestion of sport as

'a suspension of an ordinary reality in favour of an extraordinary one' (p. 64), offering a 'temporary dam against the passage of time, it makes possible the momentary dissolution of angst, the obliteration of our normal everyday concerns, in the face of the game’. (p. 65)

This was the overwhelming motivation for, and experience of, watching sport for the sojourner with no prior interest in following a team. The data suggested that the benefits emerged from not just an escape from stress, but also the need to escape to something that was meaningful to respondents, hence the importance of being a fan, in terms of having some connection to either a team or the event was highlighted, and in the case of students from countries such as Tibet or India, a connection that was often formed on relatively tenuous criteria, for example, the colour of the kit of a particular team.

A sense of belonging also emerged from the data. For the sojourner, this was borrowed through temporary support for the England side. This offered an opportunity to bond with the host community, offering a desired contact that is often elusive according to the literature on host-visitor contact. Through becoming what Guilianotti's (2002) typology would refer to as to as 'fans' of England, these individuals were able to identify temporarily with the team and generate a sense of belonging. Even though the contact was relatively short-lived, such individuals demonstrated a greater sense of identification, thus denoting the characteristics of fandom, than those associated with flaneurship. The benefits of this sense of temporary fandom were highlighted by several participants:

I enjoy watching all the games. When I watch the match in a club I have that thought I am part of England. When I support England in the club people are really friendly, they are happy to have foreigners supporting England. (Tibetan student)

If you're in a bar and supporting England, you just share information, make comments, make friends. Randomly you can share your comments with people you don't really know but you are all supporting the same team. People just share the happiness and you feel a part of society, it's really nice for me. (Indian student) 
This welcome was celebrated as something out of the ordinary, a contrast with what a number of participants described as a usually uninviting and unfriendly host population (see, e.g. Brown \& Jones, in press). Given that host contact is not usually achieved by international students, the tournament significantly permitted a valuable opportunity to reach out to and be accepted, albeit temporarily, by domestic fans.

Most are not friendly so this is good. In Africa we believe in coming together, here they don't. So this is different. It makes a change. (Nigerian student)

Everybody is very happy. It's a great contrast with normal. (Tibetan student)

Nearly all participants commented on the difficulty they found in making contact with host nationals, adding corroboration to the findings of previous studies. As Triandis, Bontempo, and Villareal (1988) point out, anomie is endemic in individualist society, and is a shock to those from cultures where the social network is tight and supportive (Wheeler, Reis, \& Bond, 1989). The tournament offered an antidote to isolation by way of the formation of a temporary community united by support for England. Thus, watching sport provides opportunities not only to forge relationships that might otherwise be unavailable, but it also allows spectators to revel in the

uniquely carnivalesque party atmosphere generated by a mega sporting event. During the World Cup, England was transformed:

People were cheering, and horns were blowing. I realised that the world cup has started and the environment is different, it's like a festival. From the environment we can say that a good thing is going on. It feels like a celebration. (Indian student)

I've never seen such things. I have heard from my father that these people are crazy about the football here. I saw so many houses and on the window was the flag. It was amazing surprise. (Indian student)

I was wondering why there were flags everywhere because I don't have TV so I went into one of my flatmates and I said 'what is happening?' My flatmate said 'it's probably just the youths having a party.' I said 'no its more than parties I can see it when people pass in cars, England, England, England, what is happening?' but later on I learnt it was going to be football. If not for the flags probably I wouldn't know but the flags really alerted me. (Nigerian student)

Everybody in the street were wearing the England flag and many cars put the England flag and many people in their living room have the England flag on the windows. I never saw this in my life, it made me happy and enthusiastic. (Chinese student)

The display of patriotism during the World Cup was striking to participants, and their reaction to this was universally positive; participants were cheered to witness the passion provoked by football. This finding sits in contrast with lingering associations between football, the England flag and the violent far right movement. As pointed out by Conn (2006), over 10 million St George flags were bought by $27 \%$ of English adults in 2006. Although (Brown \& Jones, in press) have outlined how the flag may be perceived as a signifier of potential violence, Skita (2006) argues that flag display behaviour constitutes an expression of patriotism that can exist without nationalism. Indeed, no violence was witnessed by participants despite claims that football-related violence has been forced away from stadia and into bars (Home Affairs, 2002; Institute of Alcohol Studies, 2010). Furthermore, despite evidence of an increase in football-related racism (King, 2002), no racial attack was experienced by international students during the world cup tournament. 
Yet many participants had suffered racial abuse at other times during the sojourn. Statistics show a rise in hate crime in the UK (Crown Prosecution Service [CPS], 2010; European Commission against Racism and Intolerance, 2010): that no participant faced abuse during the tournament itself is, perhaps, a function of increased security and their own vigilance. The display of flags, by contrast, had a positive function, and the excitement shown above by respondents on viewing the overt display of flags supports the view of Derbaix and Decrop (2011) that such displays may actually act to lower social norms and barriers, and provide an environment that actually promotes the sharing of experiences and socialisation between interested parties.

A third theme to emerge from the data was that of recreating home. Essential to students' enjoyment of watching was the gathering together of conationals, that is sojourners of the same nationality (Ward et al., 2001). Shared nationality allowed them to celebrate their passion for the team and the individual players. This is described by Wann et al. (2001) as bonding, constituting a further dimension of fandom. It also permitted students to compensate for and to replicate to a degree the

festivities taking place at home. Such interaction which drew conationals from a variety of networks was a comforting reminder of home.

We always met other Germans. I was really proud of my team and it was really nice to get together with other Germans and to watch all the games together. It was a really nice time. (German student)

That was on purpose because we wanted to be in a German crowd because there were not many people supporting Germany. It's just a very nice feeling supporting the same team, jumping up and down if they score a goal. It's really nice to be happy together. (German student)

I watched it with a few of my Nigerian friends in a bar. It was great. Watching the Nigeria match reminded you of home; I had a lot of flashbacks from back home. I think it was particularly emotional because the matched was played in Africa. Being with other Africans made me feel a bit more like I was at home surrounded by my people. (Nigerian student)

Armstrong and Young (1999) state that football fandom allows the creation of a comradeship of fellow fans amid spontaneous group association or partisan spectatorship. In fact, as Weed (2008) notes, it would seem that sports spectators' need for proximity is not for proximity to the event but to others sharing in the experience of watching the event. Watching their home team in the company of conationals afforded students far away from home the opportunity to bond with their country, all through the medium of football. In a study of sports, spectators attending the 2008 Beijing Olympic and Paralympic Games, Kirkup (2010) also established that the dominant benefits obtained by participants included social interaction group affiliation and a sense of belonging. This is consistent with the work of many of the major motivational models of sport consumption (see, e.g. Funk, Mahony, \& Ridinger, 2002; Trail \& James, 2001; Wann, 1995) that detail social interaction as a major motivator for sport consumption.

As Lock, Taylor, and Darcy, (2008) point out, football fandom is therefore an enabling force, providing a space to develop social ties and networks, and offering the benefits of companionship and camaraderie that would not be available otherwise. In this study, the tournament provided a stimulus for interaction, providing students with a forum for enhanced enjoyment of the games through access to shared language and shared cultural references. Brown (2009a) states that speaking 
the native language provides a physical break from the stress of communicating in a foreign language as well as an emotionally comforting reminder of home. Nevertheless, this study found that contact with home increased during the tournament, as students described themselves as driven to celebrate or commiserate with family and friends in the origin culture.

Thus, the tournament acted as a focal point not just for conational interaction in the new culture that would not otherwise have taken place but also for increased contact with home, which could not be replaced or compensated by other networks.

The final theme to emerge was that of reinforcing a sense of national identity. A move to a new culture arguably challenges a sojourner's sense of self as their familiar cultural norms are placed into question by confrontation with those of a new culture (Kim, 2001). This is all the more pertinent in the case of international

students who may face racism or distorted images of their culture (Brown, 2009b). As simply put by a Nigerian student:

Being a fan of your country gives you identity, a sense of belonging and makes you proud.

Indeed, pride was a word used recurrently to describe how students felt on watching their team:

You have joy and a sense of belonging, where you come from people are really doing something good. I'm proud as a Nigerian because they did well. (Nigerian student)

I would definitely say it really made me proud watching them play. Happiness, I felt a lot of happiness and pride. (German student)

According to Ward et al. (2001), national identification involves people's recognition, categorisation and self-identification as members of a national group, which induces a sense of affirmation and pride. The desire to see the self favourably is powerful. Ward et al. (2001) link positive self-perception and integrity of the national group. Indeed, pride was enhanced particularly when their team, and by extension their country, was received well outside their own national group:

For me listening to the English commentator saying the Greek names, that was a memorable experience, I'm ready to cry right now. I felt very good. I felt proud. I feel proud when I listen to foreign people talking about my country. I liked it. (Greek student)

This was the first time that students had witnessed an outsider view of their culture, and the result was that patriotism increased. In the context of the 2008 Beijing Olympic and Paralympic Games, a study by Shipway and Kirkup (2011) also identified the importance of the opportunity to celebrate national pride amongst sports spectators. Previously, little has been written in the sports consumption literature about this topic, although, more recently, researchers have begun to identify national pride as a reason for attending sports events (Funk, Mahony, Nakazawa, \& Hirakawa, 2001; Funk et al., 2002).

Also recurrent were references to unity, to belonging, and to being part of a community:

I felt part of a community, part of the team. We are on the same side. (Greek student)

It gives you togetherness with the others that you are with. (German student) 
Feelings of pride and togetherness are commonly enjoyed by sports fans (Jones 2000), but it is arguable that international students will derive more comfort from such feelings when they are far away from the reassuring familiarity of home. This was evident in comments made by participants: many participants described being moved to tears not only by the sight of their national team carrying their national colours but also by the coverage of their team and country in the media. As Ward et al. (2001) point out, the move to a new culture can provoke disturbing feelings of displacement and separation anxiety. It is common that patriotism increases during the international sojourn as sojourners become more culturally identified in response to changes. It can be argued then that watching their national team would serve as a powerful cultural reinforcer. The importance of the link between the team and the home nation suggests a 'traditional' sense of fandom (Guilianotti, 2002) with the sense of national identity leading to the need to follow the team, rather than the spectators simply taking advantage of the media coverage.

\section{Conclusion}

This study offers a contribution to the literature on football fandom by documenting the perspectives of international students following the FIFA World Cup tournament in 2010. The study demonstrates how watching the World Cup was life-enhancing for temporary fans, providing a sense of identity that although short-lived was able to provide a temporary sense of belonging to a community, and a sense of escape, enabling students to escape from their stressful everyday life. Secondly, it eased feelings of loneliness and homesickness by prompting the formation of temporary communities of fans, thus holding an important function during the international sojourn. For those who developed a temporary support for England, this allowed contact with members of the host community who tended usually to be elusive and hard to reach. Though contact might not be enduring, it was celebrated by participants nonetheless. Moreover, the festival atmosphere of a transformed England, manifested in an abundance of flags, was received universally positively. This finding serves to undermine the condemnation of or apprehension over flag-flying in England. On the other hand, however, participants were unaware of the negative connotations of nationalism and extremism brought by the (mis)appropriation of the England flag by right-wing groups such as the English Defence League. For permanent fans, the FIFA World Cup acted to consolidate national identity and to foster feelings of national pride. Though this might act to reaffirm national boundaries and in some instances to incite racism as reported by Weed (2008), this was not evidenced in this study.

\section{Notes on contributors}

Ian Jones is an associate dean for Sport and acting director of the Centre for Event and Sport Research at Bournemouth University. He is interested in serious leisure and fandom.

Lorraine Brown is a senior lecturer in tourism education at Bournemouth University. She is interested in cross-cultural contact and international education.

Steven Richards is a senior lecturer in tourism management at Bournemouth University. He is interested in tourism planning and host-visitor contact. 
thecarnival. In G. Finn \& R. Giulianotti (Eds.), Football culture: Local contests, global visions (pp. 173-211). London: Frank Cass.

Berry, J.W. (1994). Acculturation and psychological adaptation: An overview. In A. Bouvy, R. Van de Vijver, P. Boski, \& P. Schmitz (Eds.), Journeys into cross-cultural psychology: Selected papers from the Eleventh International Conference of the International Association for CrossCultural Psychology. Leige: Swets and Zeitlinger.

Bilyeu, J., \& Wann, D. (2002). An investigation of racial differences in sports fan motivation. International Sports Journal, 6, 94-106.

Bock, P. (1970). Culture shock. New York, NY: Alfred Knopf.

Brown, L. (2009a). An ethnographic study of the friendship patterns of international students in England: An attempt to recreate home through conational interaction. International Journal of Educational Research, 7, 232-249.

Brown, L. (2009b). A failure of communication on the cross-cultural campus. Journal of Studies in International Education, 13, 439-454.

Brown, L., \& Holloway, I. (2008). The initial stage of the international sojourn: Excitement or culture shock. British Journal of Guidance and Counselling, 36, 33-49.

Brown, L., \& Jones, I. (in press). Encounters with racism and the international student experience. Studies in Higher Education.

Conn, D. (2006, July 12). Sour English stereotypes linger amid the flag-waving. The Guardian. Retrieved http://www.guardian.co.uk/football/2006/jul/12/sport.worldcup2006.

Crawford, G. (2003). The career of the sport supporter: The case of the Manchester storm. Sociology, 37, 219-237.

Crown Prosecution Service (CPS). (2010, August 9). Racist and religious crime - CPS guidance. Retrieved from http://www.cps.gov.uk/legal/p_to_r/racist_and_religious_crime/ \#Racist

Daymon, C., \& Holloway, I. (2011). Qualitative research methods in public relations and marketing communications. London: Routledge.

De Vita, G. (2005). Fostering intercultural learning through multicultural group work. In J. Carroll, \& J. Ryan (Eds.), Teaching international students: Improving learning for all (pp. 75-83). Abingdon: Routledge.

Derbaix, C., \& Decrop, A. (2011). Colours and scarves: An ethnographic account of football fans and their paraphernalia. Leisure Studies, 30, 271-291.

Elias, N., \& Dunning, E. (1986). Quest for excitement. Oxford: Blackwell.

European Commission against Racism and Intolerance. (2010, August 10). ECRI report on the United Kingdom Strasbourg Directorate General of Human Rights and Legal Affairs. Retrieved from http://www.coe.int/t/dghl/monitoring/ecri/Country-by-country/ United_Kingdom/GBR-CbC-IV-2010-004-ENG.pdf

Funk, D., Mahony, D., Nakazawa, M., \& Hirakawa, S. (2001). Development of the sport interest inventory (SII): Implications for measuring unique consumer motives at team sporting events. International Journal of Sports Marketing and Sponsorship, 3, 291-316.

Funk, D., Mahony, D., \& Ridinger, L. (2002). Characterising consumer motivation as individual difference factors: Augmenting the sport interest inventory (SII) to explain level of spectator support. Sport Marketing Quarterly, 11, 33-43.

Furnham, A., \& Erdmann, S. (1995). Psychological and sociocultural variables as predictors of adjustment in cross-cultural transitions. Psychologia, 38, 238-251.

Garza-Guerrero, A. (1974). Culture shock: Its mourning and the vicissitudes of identity. Journal of the American Psychoanalytic Association, 22, 408-429.

Gibbons, T., \& Dixon, K. (2010). 'Surf’s up!’: A call to take English soccer fan interactions on the internet more seriously. Soccer \& Society, 11, 599-613.

Giulianotti, R., \& Robertson, R. (2004). The globalization of football: A study in the globalization of the 'serious life'. The British Journal of Sociology, 55, 545-568.

Gu, Q., Schweisfurth, M., \& Day, C. (2008). A comparative study of international students’ intercultural experiences. Nottingham: Nottingham University.

Guilianotti, R. (2002). Supporters, followers, fans, and flaneurs: A taxonomy of spectator identities in football. Journal of Sport and Social Issues, 26, 25-46.

Hall, E. (1959). The silent language. New York, NY: Double Day.

Hamburg, D., \& Adams, J. (1967). A perspective on coping behaviour: Seeking and utilising information in major transitions. Archives of General Psychiatry, 17, 277-284.

Hennink, M., Hutter, I., \& Bailey, A. (2011). Qualitative research methods. London: Sage.

Holloway, I., \& Wheeler, S. (2010). Qualitative research in nursing and healthcare. Oxford: Blackwell. 
Home Affairs. (2002). The football disorder amendment bill. House of Commons. Retrieved from http://www.parliament.uk/documents/commons/lib/research/rp2001/rp01-073.pdf 



